\title{
TWO-CAR IMPACT TEST OF CRASH-ENERGY MANAGEMENT PASSENGER RAIL CARS: ANALYSIS OF OCCUPANT PROTECTION MEASUREMENTS
}

\author{
Kristine J. Severson \\ Daniel P. Parent \\ David C. Tyrell \\ Volpe National Transportation Systems Center \\ U.S. Department of Transportation \\ Cambridge, MA 02142
}

\begin{abstract}
As a part of ongoing passenger rail equipment safety research, a full-scale impact test of two cars with energy absorbing end structures was carried out on February 26, 2004. In this test, two coupled cars impacted a rigid barrier at 29 $\mathrm{mph}$. Similar to previous full-scale tests in the series $[1,2,3]$, anthropomorphic test devices (or ATDs) were included on the rail cars to measure the occupant response during the collision. These ATDs were instrumented with accelerometers and load cells to measure the injury risk to the occupants. This paper presents preliminary tests results.

Five occupant experiments were included in the two-car test. Three of the experiments were similar to those conducted on the two-car test of conventional equipment that was held on April 4, 2000: forward-facing occupants in inter-city seats, forward-facing occupants in commuter seats, and rear-facing occupants in commuter seats. Two of the experiments examine the interaction of an occupant with a workstation table in a facing-seat configuration. These two tests used experimental ATDs with an increased capacity for recording abdominal impact response. To aid the analysis of this problem, MADYMO computer models were developed for four of the five of the occupant experiments. The models were either modified from earlier simulations, in the case of the commuter seats, or newly developed, in the case of the inter-city seats and table experiment with THOR ATD. The models were validated based on previous tests and/or accident data. Predictions of the ATD response agree closely for the overall kinematics of the ATDs, and for many of the measurements made with the ATDs in the full-scale test.
\end{abstract}

\section{INTRODUCTION}

In support of the Federal Railroad Administration, a series of in-line full-scale impact tests have been conducted to evaluate and improve the crashworthiness of passenger rail vehicles. Table 1 lists the test conditions and date. Three in-line collision tests have been conducted using existing conventional equipment. The test described in this paper is the second inline impact test using improved crashworthiness design equipment.

The principle objective of this test was to demonstrate the collision performance of coupled cars modified with end structures designed to absorb energy through controlled crush, and to compare the collision behavior of the modified cars with that of existing conventional passenger cars. For this test, the end structures of two existing conventional cars were removed and replaced by crash energy management (CEM) end structures. The purpose of the CEM design is to preserve the occupied area of the car during a collision. More detail on the structural aspects of the test can be found in References [4] and [5].

Table 1. In-Line Passenger Equipment

Full-Scale Impact Tests with Nominal Impact Speeds

\begin{tabular}{|l|c|c|}
\hline \multicolumn{1}{|c|}{ Test Conditions } & $\begin{array}{c}\text { Improved } \\
\text { Conventional } \\
\text { Equipment }\end{array}$ & $\begin{array}{c}\text { Crashworthiness } \\
\text { Design } \\
\text { Equipment }\end{array}$ \\
\hline $\begin{array}{l}\text { Single-car impact with } \\
\text { fixed barrier }\end{array}$ & $\begin{array}{c}\text { Nov. 16, 1999 } \\
35 \mathrm{mph}\end{array}$ & $\begin{array}{c}\text { Dec 3, 2003 } \\
34 \mathrm{mph}\end{array}$ \\
\hline Two-coupled-car impact & Apr. 4, 2000 & Feb. 26, 2004 \\
with fixed barrier & $26 \mathrm{mph}$ & $29 \mathrm{mph}$ \\
\hline Cab car-led train impact & Jan. 31, 2002 & Planned for 2005 \\
with locomotive-led train & $30 \mathrm{mph}$ & \\
\hline
\end{tabular}

While the CEM design preserves more occupied area of the car during a train collision, it comes at the expense of a more severe secondary impact environment for occupants seated in the leading car or two of the train. To assess injury risk in 
different seating configurations, five occupant experiments were designed. The occupant experiments and their placement in the cars are depicted in Figure 1 and 2.

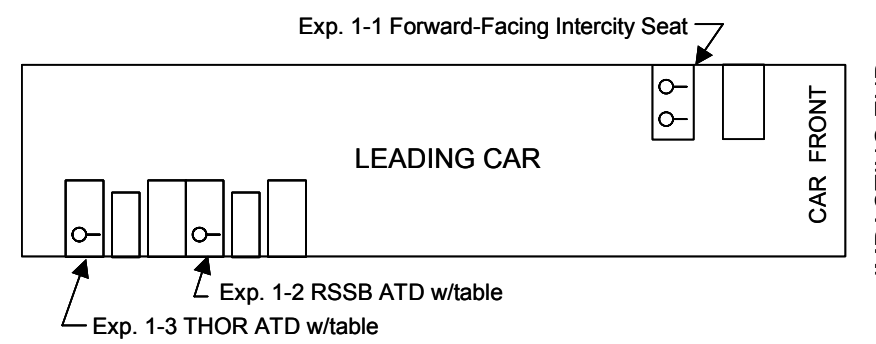

Figure 1. Location of Leading Car Occupant Experiments

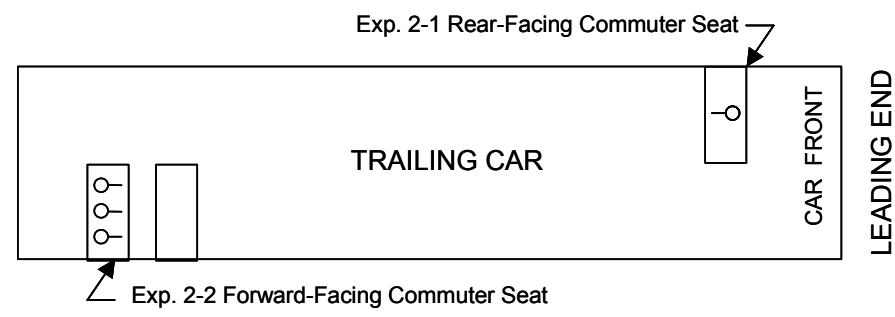

Figure 2. Location of Trailing Car Occupant Experiments

\section{DESCRIPTION OF OCCUPANT EXPERIMENTS}

A collision dynamics model of the CEM two-car impact test indicated that the modified force/crush behavior of the cars would result in a more severe secondary impact environment than in the two-car conventional test [4]. Secondary impact refers to the impact between the occupant and some part of the interior, usually the forward seat, table or bulkhead. While the CEM design was expected to better preserve occupied space, previous analysis [6] has indicated that the secondary impact velocity in a two-car CEM test could be $40-85 \%$ higher than in a comparable conventional test.

There are two necessary elements to protect occupants during a collision. It is first necessary to compartmentalize the occupants. Compartmentalization refers to limiting the trajectory of the occupant, usually within the space between the launch seat and the impacted seat. If compartmentalization is lost, there exists a risk that the occupant kinematics are less predictable, and there is a risk of striking more volatile surfaces. Compartmentalization has been shown to be an effective occupant protection strategy [7]. Second, the loads and accelerations imparted on the occupants by the seating arrangements that act in compartmentalizing the occupants must be within maximum injury criteria values. These two necessary elements are evaluated by the five occupant experiments.

Three of the occupant experiments (Exp. 1-1, 2-1, and 2-2) used seating arrangements that have been previously included in the conventional full-scale tests, as well as in sled testing. These seats have been modified as determined necessary from each testing iteration. Two of the occupant experiments examine the interaction of an occupant with a workstation table in a facing-seat arrangement. In addition to the aforementioned objectives, these experiments sought to collect information necessary for specifying the design requirements of an improved crashworthiness workstation table.

A secondary objective of the tests was to gather data to refine and validate computer models of each occupant experiment. As more test data is collected on each seat type and configuration, the computer models can be used more reliably to estimate the injury risk of many different collision scenarios.

\section{Experiment 1-1 - Forward-Facing Inter-City Seats,} Two 95 $^{\text {th }}$ Percentile Males, Leading Car

Experiment 1-1 consisted of two pairs of forward-facing inter-city seats, with a seat pitch of 41 inches. These seats were modified in the same manner as the inter-city seats in the twocar and train-to-train conventional tests, including strengthened seat backs with an energy absorber in the base. These modifications were necessary to ensure compartmentalization of the occupant during a collision. See Reference [3] for more detail on the inter-city seat modifications. The objective of this experiment was to determine if these modifications sufficiently protect the occupant in a more severe collision environment.

Two Hybrid III $95^{\text {th }}$ percentile male ATDs were positioned in the rear seat pair. A pre-test photo of Experiment 1-1 is shown in Figure 3. Note that the duct tape shown in these photographs holds the ATDs in their initial positions during the car's approach to the impacted wall, and is perforated so it does not affect their motion during the impact. The experiment was located near the front of the leading car that impacted the wall. The ATDs were unrestrained, as were all the ATDs in the twocar CEM test. Both ATDs were instrumented to measure the tri-axial head and chest acceleration, axial femur load, shear and axial neck loads, and neck flexion/extension moment. A floor-mounted bi-axial accelerometer also measured the longitudinal and vertical car acceleration.

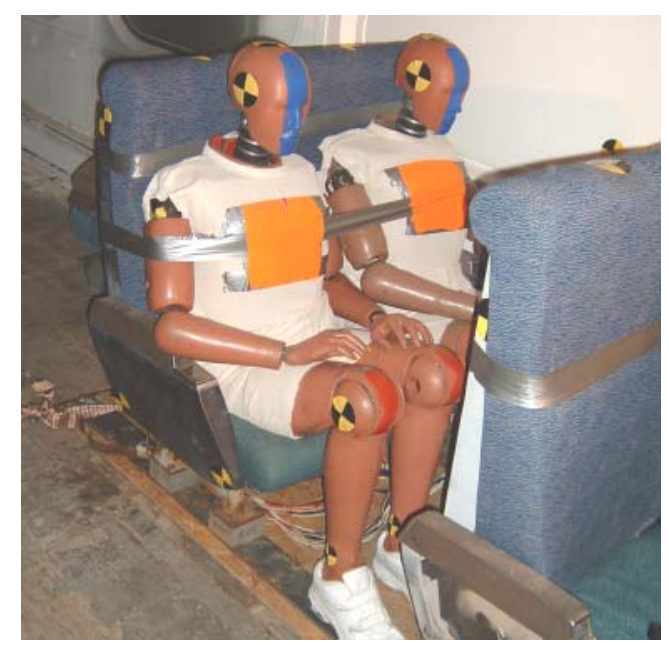

Figure 3. Pre-Test Photo of Experiment 1-1 
The pre-test MADYMO [8] computer model predicted a high likelihood of exceeding the head, neck and femur criteria, with a low probability of exceeding the chest acceleration criteria. While the seat backs are expected to rotate about the seat base about thirty degrees, the occupants are expected to remain compartmentalized.

\section{Experiment 2-1 - Rear-Facing Commuter Seat, One $\underline{50}^{\text {th }}$ Percentile Male, Trailing Car}

Experiment 2-1 consisted of a single modified rear-facing three-person M-Style commuter seat. The modified seat was similar to the seat tested in the trailing car of the two-car conventional test [2]. Seat modifications included a strengthened floor pedestal/attachment and frame stiffeners between the seat back and seat base. The objectives of this experiment were to ensure that the seat attachments were sufficient to compartmentalize the occupant, and to show that rear-facing seats are an effective occupant protection strategy.

One Hybrid III $50^{\text {th }}$ percentile ATD was positioned in the middle seat position (see Figure 4). The experiment was located near the front of the trailing coach car. The ATD was instrumented to measure tri-axial head and chest acceleration, shear and axial neck loads, and neck flexion/extension moment.

The pre-test MADYMO computer model predicted a low likelihood of exceeding the head, chest and femur criteria, with a moderate probability of exceeding the neck criteria.

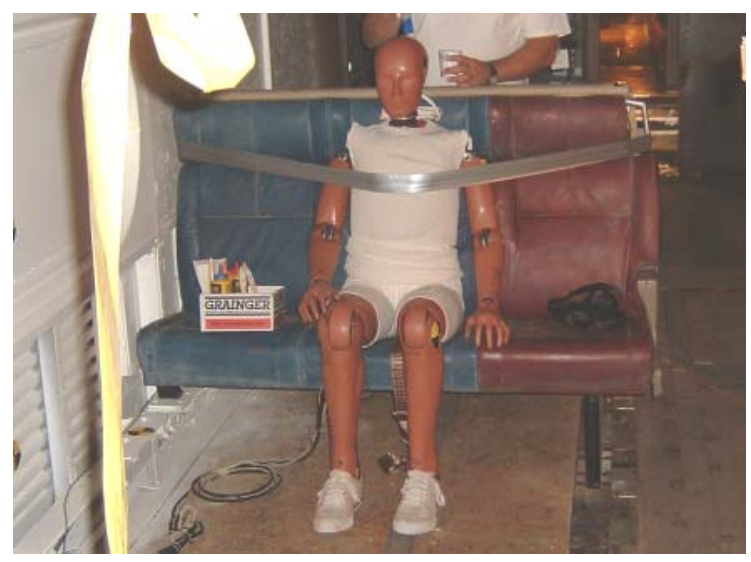

Figure 4. Pre-Test Photo of Experiment 2-1

\section{Experiment 2-2 - Forward-Facing Commuter Seat, Three 50 ${ }^{\text {th }}$ Percentile Males, Trailing Car}

Experiment 2-2 consisted of two forward-facing threeperson M-Style commuter seats. The forward seat was modified as described above for Experiment 2-1. Instrumented Hybrid III $50^{\text {th }}$ percentile male ATDs were located in the window and aisle positions of the rear seat. An uninstrumented Hybrid II $50^{\text {th }}$ percentile male ATD was located in the middle seat position (see Figure 5). The ATDs in the window and aisle seats were instrumented to measure tri-axial head and chest acceleration, axial femur load, shear and axial neck loads, and neck flexion/extension moment. A floor-mounted bi-axial accelerometer also measured the longitudinal and vertical acceleration.
The pre-test MADYMO computer model predicted a high likelihood of exceeding the head, neck and femur criteria, with a low probability of exceeding the chest acceleration criteria.

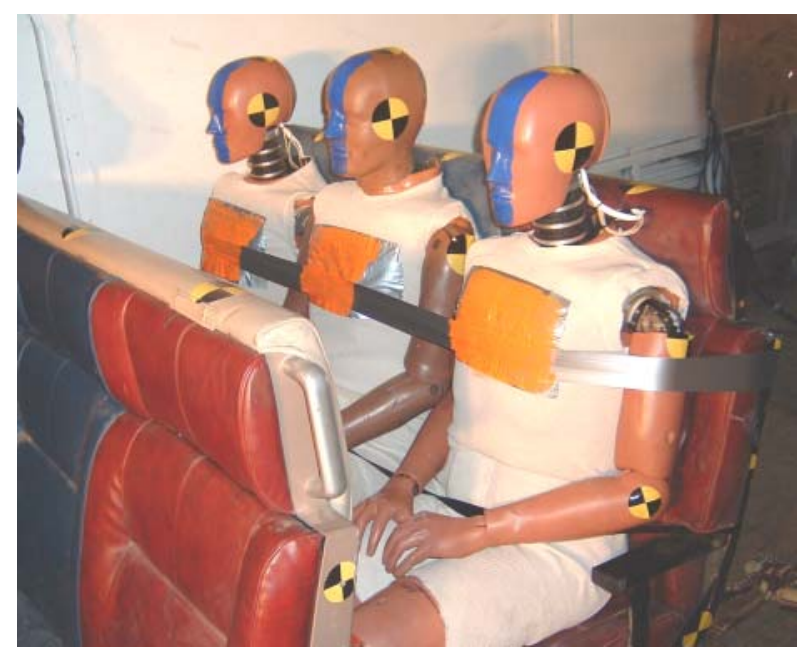

Figure 5. Pre-Test Photo of Experiment 2-2

\section{Experiments 1-2 and 1-3 - Facing Seats with Tables}

Two new occupant experiments were conducted in this test using ATDs seated at workstation tables (Exp. 1-2 and 1-3). The impetus for these experiments was a rail accident in which a MetroLink passenger train collided with a BNSF freight train that occurred in Placentia, CA on April 23, 2002. Two of the three fatalities were likely caused by abdominal/chest injuries due to impact with a workstation table [9].

The objective of the experiments with tables was to gather information about the crashworthiness behavior of this seating configuration, in order to develop potential countermeasures. In general, abdominal injuries are not as well understood as head, chest, neck and femur injuries. There exist suggested injury criteria but there are no governmental criteria for abdominal injuries. The standard Hybrid III ATDs do not have instrumentation to measure abdominal forces or penetration.

Another objective of the table experiments was to collect and compare test data from two experimental ATDs subjected to the same collision conditions. The ATDs used in the table experiments were the THOR (Test Device for Human Occupant Restraint) [10] and the Hybrid 3RS (not currently documented). The $50^{\text {th }}$ percentile male THOR Alpha ATD is a product of the National Transportation Biomechanics Research Center of the National Highway Traffic Safety Administration (NHTSA). Version 1.1 was released in December 2001. It has improved biofidelic features and has significantly enhanced instrumentation capabilities.

Transportation Research Laboratories, Limited (TRL, LTD.) developed the Hybrid 3 Rail Safety (RS) test dummy under the direction of the United Kingdom's Rail Safety and Standards Board. The Hybrid 3RS uses the standard Hybrid III head, neck, arms, legs, upper thorax, and several spine 
components and incorporates the CRUX thoracic displacement measurement devices, spine flex joint, lower abdomen insert including double-gimballed string potentiometer (DGSP) units, and pelvis from the THOR.

\section{Experiment 1-2 - Forward-Facing Commuter Seat with Table, One Hybrid 3RS ATD, Leading Car}

Experiment 1-2 consisted of a single Hybrid 3RS ATD seated in the window position of a forward-facing commuter seat, at a workstation table (see Figure 6). The pitch of the facing-seat arrangement is 65 inches, with the table centered between the two pairs of seats. The tabletop is 33.5 inches long by 16 inches wide by 1.2 inches thick solid wood. The top of the table is 29.75 inches from the floor. Both the facing seats and table are similar to those on the Metrolink cab car in the Placentia, CA collision. The wall and floor attachments of the table to the car body were strengthened to ensure compartmentalization and allow measurement of the peak load imparted by the occupant. The ATD was instrumented to measure tri-axial head and bi-axial chest acceleration, axial femur load, shear and axial neck loads, neck flexion/extension moment, bi-lateral three-dimensional displacements of the abdomen, and bi-lateral three-dimensional displacements of the upper and lower rib cage. In addition, the table has multiple transducers to measure force, displacement and acceleration.

A pre-test computer model was not implemented, as a model of the Hybrid 3RS ATD does not exist.

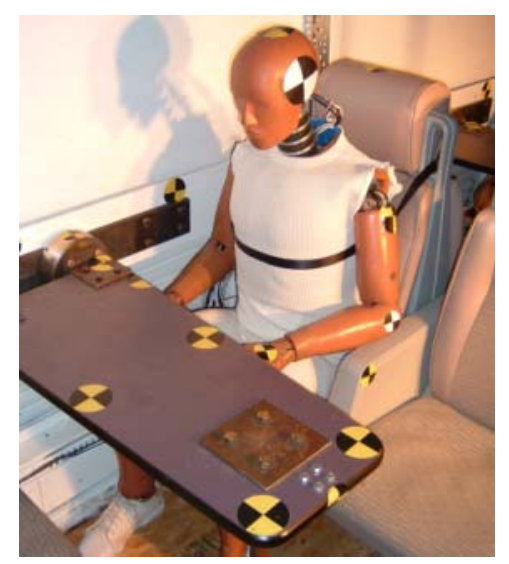

Figure 6. Pre-Test Photo of Experiment 1-2

\section{Experiment 1-3 - Forward-Facing Commuter Seat with Table, One THOR ATD, Leading Car}

Experiment 1-3 consisted of a single THOR ATD seated in the window position of a forward-facing inter-city seat, at a workstation table (see Figure 7). This seating arrangement is identical to Experiment 1-2. The ATD was instrumented to measure nine-axis head and 6-axis chest acceleration, axial femur load, shear and axial neck loads, neck flexion/extension moment, upper abdominal acceleration, upper abdominal linear displacement, and bi-lateral three-dimensional displacements of the lower rib cage. In addition, the table has multiple transducers to measure force, displacement and acceleration.
The pre-test MADYMO computer model predicted a high likelihood of exceeding the criteria for abdominal penetration and rate of penetration, as well as peak chest deceleration. The model predicted that the head would strike the top of the table, but the HIC and Nij criteria would not be exceeded.

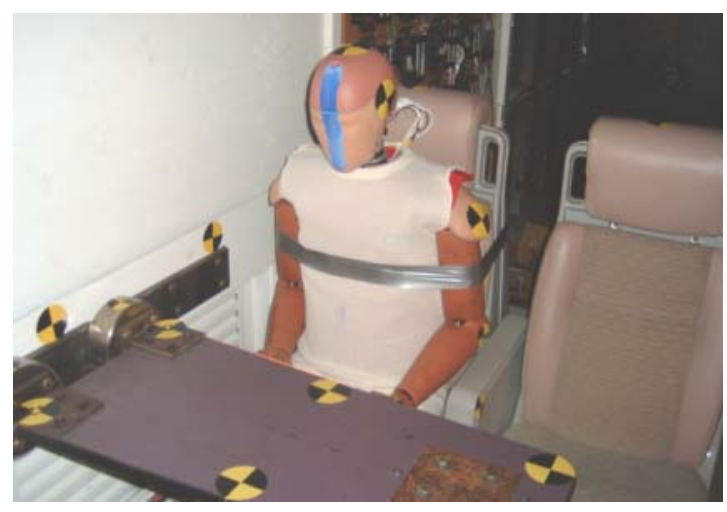

Figure 7. Pre-Test Photo of Experiment 1-3

\section{OCCUPANT EXPERIMENT RESULTS}

During an in-line frontal collision, the longitudinal acceleration-time history, or crash pulse, has the most significant influence on the severity of the secondary impact for the occupants. In the two-car CEM test, the force/crush characteristic of the CEM design results in a crash pulse with a relatively high average longitudinal acceleration as compared with the $8 \mathrm{G}$ triangular crash pulse that has been used in sled testing of rail seats [11], and compared to the conventional twocar test results.

The longitudinal acceleration-time history for each car is plotted in Figure 8. The data for each curve were taken from the accelerometer on the center sill near the longitudinal center of the respective cars. The data were then filtered using a CFC 60 filter, as recommended in SAEJ211/1 [12]. There is ringing in the car body acceleration data at less than $100 \mathrm{~Hz}$; however, if filtered at a lower frequency, significant data would be lost. Reference [13] justifies this filter choice.

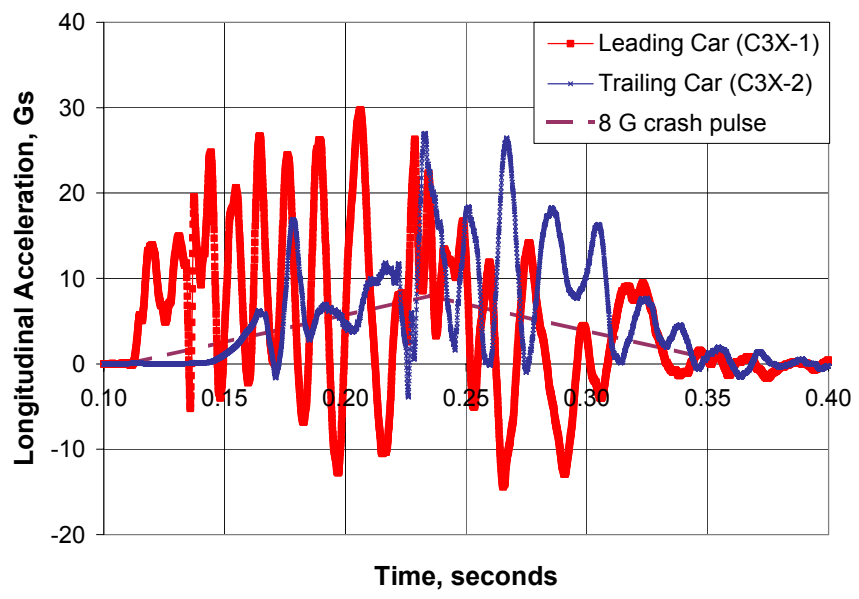

Figure 8. Longitudinal Car Acceleration 
As compared to the crash pulses from the conventional twocar test, the initial peak is much lower, but the average peak value increases with time. Another way to look at the influence of the crash pulse is to plot the relative velocity of an occupant with respect to the car against the relative displacement. This plot of relative motion accounts for the whole acceleration time-history, which is more important than the peak values. Relative impact velocity can be used as a simple method to estimate the severity of different collisions with different crash pulses.

The occupant's velocity relative to the car increases with the distance traveled relative to the car within a range of typical seat pitches. At larger relative displacements, the secondary impact velocity reaches an asymptote of roughly the closing speed plus rebound. The higher the secondary impact velocity (SIV), the greater the likelihood of occupant injury. A comparison of SIV for the conventional and CEM designs, shown in Figure 9, suggests the trade-off in performance associated with the higher average accelerations in the CEM design. At 2 feet of travel, the SIV is $13 \mathrm{mph}$ for the conventional design and 22-25 mph for the CEM design. Two feet is the approximate distance an occupant in the forwardfacing commuter seat configuration would travel before impacting the forward seat.

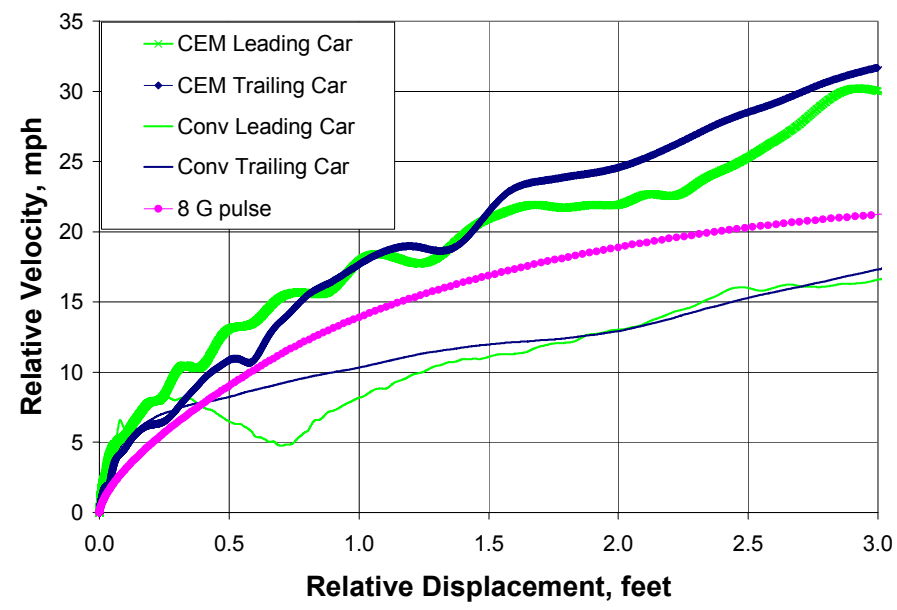

Figure 9. Relative Velocity vs. Relative Displacement
As expected, the secondary impact environment was quite severe for the ATDs in this test, when compared to the previous in-line full-scale impact tests. Based on the dummy kinematics, the lateral and vertical car body accelerations appear to be less significant than in the conventional tests. All of the ATDs were effectively compartmentalized, with the exception of the ATDs in the forward-facing commuter seats. In this experiment, the seat back deformed sufficiently to allow the ATDs to travel over the top of the forward seat back. Only the ATDs in the workstation table seating arrangements exceeded the injury criteria for chest deceleration. None of the ATDs exceeded the injury criteria for peak tension/compression neck load or axial femur load. Only the ATDs in the forward-facing inter-city seat exceeded the maximum Head Injury Criterion (HIC). Neither of the ATDs in the seats with table experiments exceeded the suggested injury criteria for abdominal compression and rate of compression. Details about each occupant experiment are given below. For comparison, results from previous full-scale impact tests are provided in the Appendix.

In a train-to-train collision with CEM cars, the cab car environment will be more severe than a similar collision involving conventional equipment. The environment in the $1^{\text {st }}$ coach will be moderately worse compared to conventional equipment, and the environment in the trailing cars will be about the same. Protecting occupants from secondary impact injuries in the CEM cab car is the principal concern.

\section{Experiment 1-1 - Forward-Facing Inter-City Seats, Two $5^{\text {th }}$ Percentile Males, Leading Car}

As the leading car collided with the wall, the aisle and window dummies began to translate forward away from the rear seat. The knees impacted the seat back panels, which both deformed severely during the impact. At the same time, the seat backs rotated about the seat base about 15 degrees. At this point, the dummies rotated forward at the pelvis and the heads impacted the top of the seat backs. This caused the seat backs to rotate an additional 10 degrees. The feet and legs of the dummies rose off the ground, and the knees impacted the attachment point of the seat back to the seat base as the dummies fell. The chins also impacted the top of the seat backs as the dummies fell. A series of pictures taken from high-speed film during the test is shown in Figure 10.

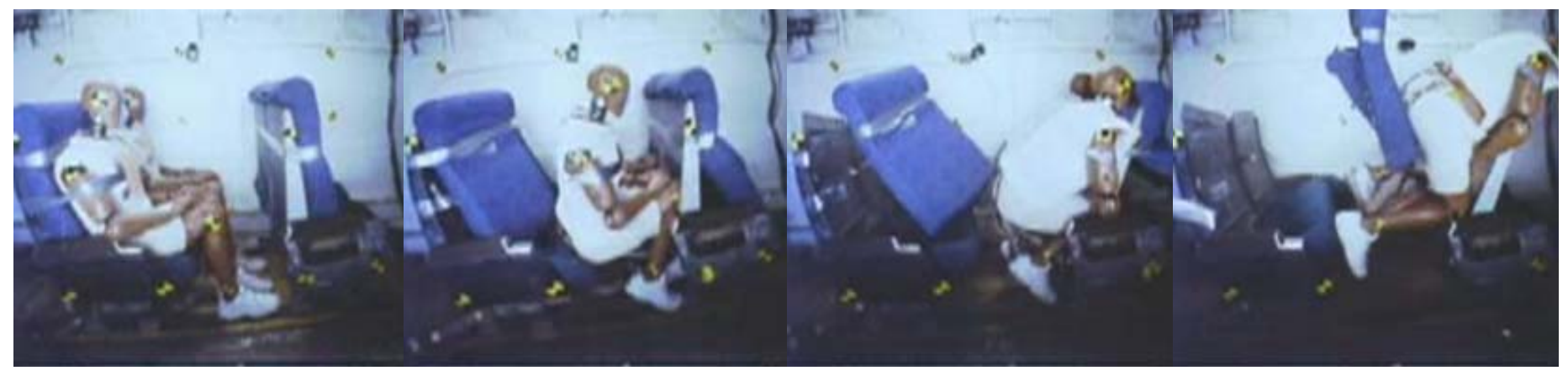

Figure 10. Time-Sequence for Experiment 1-1, Forward-Facing Inter-City Seats, Leading Car 
Both dummies remained compartmentalized during the collision. The HIC was exceeded in both the aisle and window dummies. The Nij criteria indicated a high risk of neck injury in the compression-flexion case for both dummies. This event occurred as the head first impacts the seat back. The face remains in contact with the seat back as the body continues to translate forward and rotate upwards about the knee contact, bringing about compression and flexion of the neck. The chest acceleration criterion is relatively low in both dummies. The femur loads approach, though do not exceed, the maximum criteria value. See Table 2 for measured injury results.

Table 2. Experiment 1-1 Preliminary Injury Results for $9^{\text {th }}$ Percentile Male

\begin{tabular}{|l|c|c|c|}
\hline Criteria & $\begin{array}{c}\text { Injury } \\
\text { Threshold } \\
{[14]}\end{array}$ & $\begin{array}{c}95^{\text {th }} \text { Percentile } \\
\text { Male, Window } \\
\text { Seat }\end{array}$ & $\begin{array}{c}95^{\text {th }} \text { Percentile } \\
\text { Male, Aisle } \\
\text { Seat }\end{array}$ \\
\hline HIC15 & 700 & $\begin{array}{c}2,600 \\
(3.3 \mathrm{~ms})\end{array}$ & $\begin{array}{c}3,849 \\
(1.6 \mathrm{~ms})\end{array}$ \\
\hline Window) & & $0.39(\mathrm{Ntf})$ & $0.43(\mathrm{Ntf})$ \\
& 1.0 & $0.60(\mathrm{Nte})$ & $0.32(\mathrm{Nte})$ \\
Nij & & $0.85(\mathrm{Ncf})$ & $0.77(\mathrm{Ncf})$ \\
& $+1,131 /-$ & $+409 /-935$ & $+422 /-465$ \\
\hline Peak Neck & 1,089 & 19.8 & 26.4 \\
Fz, lbf & 55 & 1,090 & 2,056 \\
Chest G & 2,850 & 1,976 & 1,444 \\
\hline Femur & & & \\
Load, lbf & & &
\end{tabular}

There was plastic deformation of the seat back panels in both of the impacted seats. The panels caved inwards when impacted by the knees of the dummies and began to pull out the rivets at the bottom of the seatback. The seat pedestal itself did not deform, but the seat track bowed roughly half an inch upward at the rear pedestal attachment and downward at the front pedestal attachment.

The results from this experiment show that the modified seat back of the inter-city seat is sufficient to compartmentalize the occupants under this more severe occupant environment. The seat back deflection absorbed some energy during the impact; however, additional padding is necessary at the top of the seat back to reduce the risk of head injury. The high HIC values measured require further analysis; one questionable aspect is the extremely small time window of the peak head accelerations.
Experiment 2-1 - Rear-Facing Commuter Seat, One $\underline{50}^{\text {th }}$ Percentile Male, Trailing Car

The rear-facing seat experiment was the most benign of all the experiments in the two-car CEM impact test. The sole ATD in the middle seat was already in contact with the seat back and therefore did not develop a significant velocity with respect to the seat. As shown in Figure 11, the seat back is not tall enough to support the ATD's head, resulting in a moderate tension-extension neck load. The injury criteria shown in Table 3 are all well below the injury thresholds. The ATD fell onto the floor after the impact, but had there been another row of seats in front, he likely would have remained sitting on the launch seat.

Table 3. Experiment 2-1 Preliminary Injury Results

\begin{tabular}{|l|c|c|}
\hline Criteria & $\begin{array}{c}\text { Injury } \\
\text { Threshold } \\
{[15]}\end{array}$ & $\begin{array}{c}50^{\text {th }} \text { Percentile Male, } \\
\text { Middle Seat }\end{array}$ \\
\hline HIC15 & 700 & 94 \\
\hline Nij & 1.0 & $\begin{array}{l}0.07(\mathrm{Ntf}) \\
0.62(\mathrm{Nte}) \\
0.05(\mathrm{Ncf}) \\
0.10(\mathrm{Nce})\end{array}$ \\
\hline Peak Neck & $+937 /-899$ & $+430 /-94$ \\
Fz, lbf & 60 & 14 \\
\hline Chest G & 2250 & N/A \\
\hline Femur Load, & & \\
lbf & & \\
\hline
\end{tabular}

The seat remained attached and there was minimal deformation of the seat attachment brackets at the wall mount. There was no visible deformation of the floor pedestal. The inertia from the combined mass of the ATD and the seat caused a good deal of permanent bending of the vertical frame members in the seat back.

The results from this experiment show that the modifications to the rear-facing commuter seat are sufficient to compartmentalize one occupant. There is a potential concern that the seat back may have deformed too severely to provide compartmentalization had the seat been loaded by three ATDs rather than just one. The injury risk due to the occupant interaction with the seat is very low, indicating that rear-facing seats are an effective occupant protection strategy.

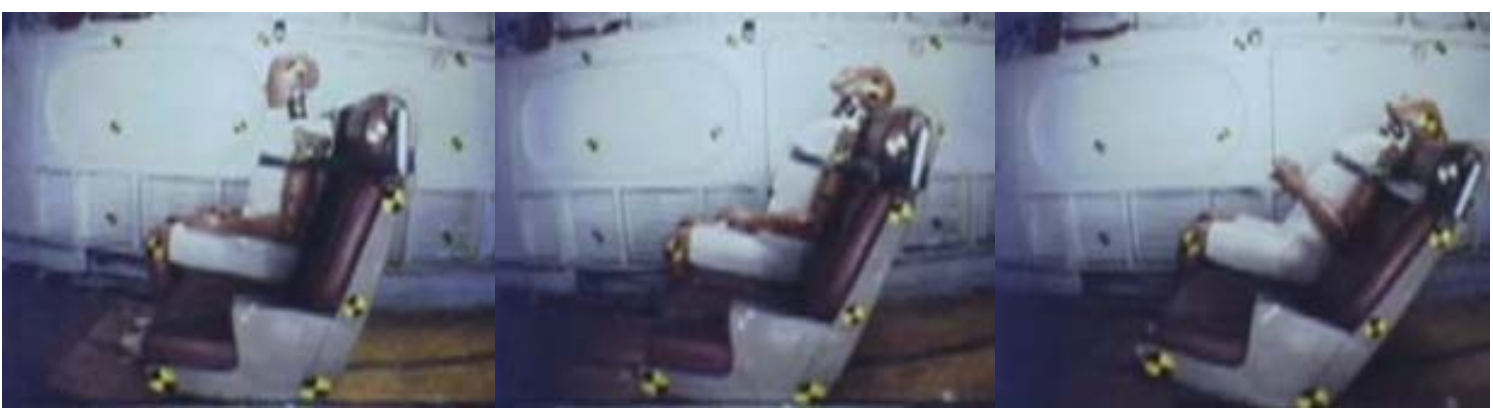

Figure 11. Time-Sequence for Experiment 2-1, Rear-Facing Commuter Seat, Trailing Car 


\section{Experiment 2-2 - Forward-Facing Commuter Seats,} Three 50 ${ }^{\text {th }}$ Percentile Males, Trailing Car

During the collision, the ATDs slid forward in the seat until the knees struck the back of the forward row of seats, instigating severe deformation of the seat back. Next the heads and chests struck the seat back as it continued to deform, resulting in relatively low head and chest impact forces. The ATDs' forward motion took them over the top of the forward seat back. The tethers tying the ATDs to the floor prevented them from traveling further. The time-sequence of pictures shown in Figure 12 was taken from an overhead camera. Sideview pictures were not available because that camera was damaged during the test.

None of the occupants in this experiment were compartmentalized. Because the seat back deformed and provided little resistance, the injury criteria are all quite low. Also, the ATDs did not impact other interior structures because the additional seats were removed and tethers limited the travel of the ATDs. Since the first necessary element to occupant protection was not achieved, the injury criteria measurements are disregarded.

Originally the continuous steel frame members running vertically down the seat back and longitudinally under the seat base were preformed at an angle of approximately 110 degrees. After deforming under the load of the ATDs, the angle of these members was about $45^{\circ}$. The seat base and pedestal were mostly intact. The forward wall-mounting bracket collapsed while the rear bracket fractured. The square tube connecting the seat back to the seat base on the wall side failed just in front of the gusset. All of the seat cushions from the rear seat as well as the cushions from the seat back of the forward seat detached from the seat frames and became hazardous free-flying objects. The frame of the rear seat in which the ATDs were originally seated experienced no visible deformation. The attachments to the floor pedestal and the wall were also intact.

The results of this experiment show that the forward-facing commuter seats require further modification. The extreme deformation/failure of the seat back and wall attachment brackets prevented compartmentalization of the occupants. The occupants were not sufficiently protected in a collision of this severity.

\section{Experiment 1-2 - Forward-Facing Inter-City Seats} with Table, One Hybrid 3RS, Leading Car

Upon impact, the Hybrid 3RS translated directly forward in the longitudinal direction. There was little or no displacement in the vertical or lateral directions. The dummy's shoes initially began to slide along the floor, and then dragged enough to cause rotation about the knee. The knees contacted the facing seat pan at the same time as the upper abdomen impacted the table. Upon impact with the table, the upper abdomen compressed nearly half the depth of the dummy. As this compression occurred, the upper body rotated forward and down towards the table, while the pelvis and legs rotated slightly upwards towards the table. At the point of maximum compression, the dummy slid backwards and returned to the initial seating position. See Figure 13 for photos of the timeresponse.

The HIC, Nij, neck tension/compression, chest acceleration, and femur loads were all below the maximum injury criteria values. Preliminary results show a high peak abdominal load and significant abdominal compression and rate of compression. These measurements are consistent with the photometric evidence illustrated in Figure 13, though the lower thoracic bi-lateral displacement measurements need to be verified. See Table 4 for measured injury results. Note that an abdominal compression of $50 \%$ corresponds to a $25 \%$ probability of an AIS $\geq 4$ abdominal injury [16].

There were no signs of failure in any of the seating arrangements. The displacement of the table was minimal, and returned to its original position after the impact. The peak table load measured at the location of the impact was 6,490 pounds. While this seating arrangement was successful in compartmentalizing the occupant, the injury risk associated with the table impact is very high. Thus, an occupant seated at a workstation table is not sufficiently protected during a collision of this severity.
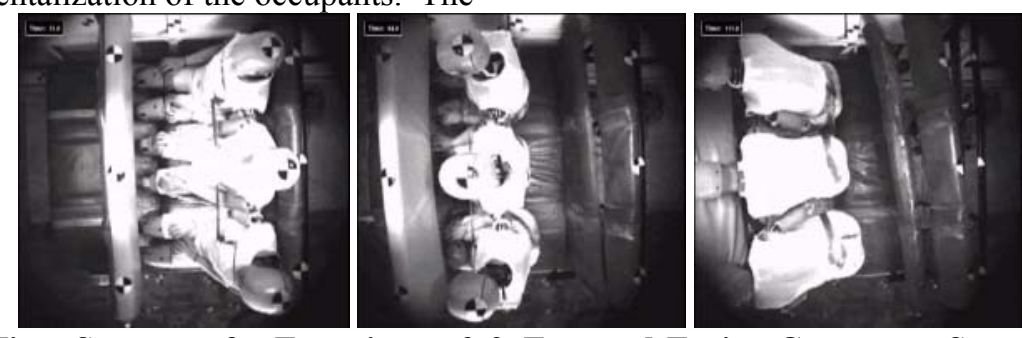

Figure 12. Time-Sequence for Experiment 2-2, Forward-Facing Commuter Seat, Trailing Car
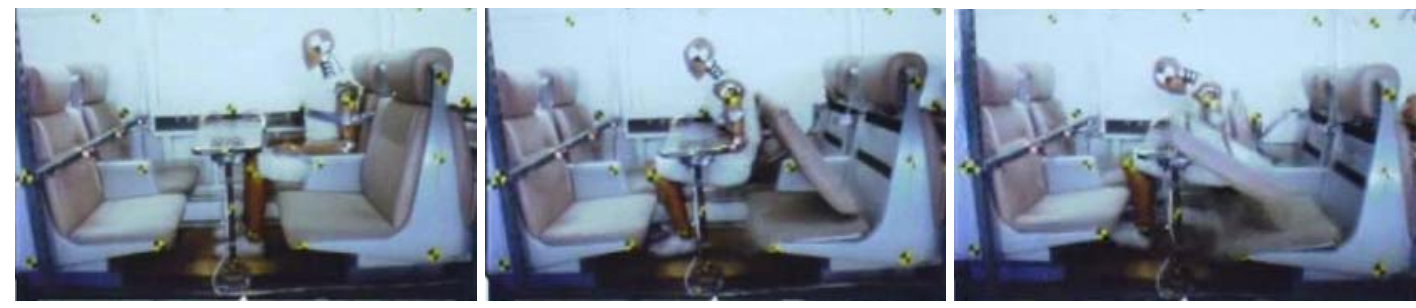

Figure 13. Time-Sequence for Experiment 1-2, Hybrid 3RS with Table, Leading Car 
Table 4. Experiment 1-2 Preliminary Injury Results for Hybrid 3RS

\begin{tabular}{|l|c|c|}
\hline \multicolumn{1}{|c|}{ Criteria } & $\begin{array}{c}\text { Injury } \\
\text { Threshold }\end{array}$ & $\begin{array}{c}\text { Hybrid 3RS Male, } \\
\text { Window Seat }\end{array}$ \\
\hline HIC15 & 700 & 215 \\
\hline Nij & 1.0 & $\begin{array}{l}0.34(\mathrm{Ntf}) \\
0.60(\mathrm{Nte}) \\
0.07(\mathrm{Ncf}) \\
0.32(\mathrm{Nce})\end{array}$ \\
\hline Peak Neck Fz, lbf & $+937 /-899$ & $+558 /-93$ \\
\hline Chest G & 60 & 45.8 \\
\hline Femur Load, lbf & 2,250 & $417 / 652$ \\
\hline Upper Abdomen & $50 \%$ & $37.1 \%$ \\
Compression & & 1.08 \\
Ratio (mm) [16] & & \\
\hline Upper Abdomen & 1.98 & \\
V*C (m/s) [17] & & \\
\hline
\end{tabular}

\section{Experiment 1-3 - Forward-Facing Inter-City Seat with Table, One THOR ATD, Leading Car}

As the THOR impacted the workstation table, the rotation of the upper body about the point of impact was severe. The head pitched downward and struck the forward edge of the table. Since the dummy jacket was wedged between the upper and lower abdominal inserts after the impact, it is likely that the table edge initially contacted the upper abdomen insert, then slid into the gap between the upper and lower abdomen inserts and impacted the spine. This event brought about a high chest acceleration peak. See Figure 14 for photos of the timeresponse.

Aside from the peak chest acceleration, the measured injury criteria values were within survivable limits. The abdominal compression and the rate of abdominal compression were below the suggested maximum injury criteria values. However, the validity of this measurement as an index of injury is questionable in this case. The measured compression was lower than the total compression of the upper abdomen, due to the fact that the table edge penetrated between the upper and lower abdominal inserts and below the lowest rib, where the lower thoracic bi-lateral displacement transducer is attached. Had the table impact remained squarely on the upper abdominal insert, the penetration of the table into the abdominal cavity would have been reduced, and the spine would not have been impacted. See Table 5 for measured injury results.

As in experiment $1-2$, the table was minimally displaced during the impact, and returned to its original position afterwards. The peak table load measured at the location of the impact was above 6,813 pounds. There were no signs of failure in any of the seat or table attachment point. Again, while this seating arrangement compartmentalizes the occupant, the injury risk associated with the table impact is very high.

The kinematics of the Hybrid 3RS and the THOR ATDs differed greatly. In the impact with the table, both ATDs showed upper body rotation down towards the top of the table, and lower extremity and pelvis rotation up towards the bottom of the table. However, the THOR rotations were large enough that the head impacted top of the table and the knees impacted the bottom of the table. Thus, the THOR measured higher HIC and $\mathrm{Nij}$ values than the Hybrid 3RS. The peak chest acceleration was also higher for the THOR, as the table edge bypassed the abdominal inserts and directly impacted the spine. The Hybrid 3RS includes a PTFE bib between the abdomen and rib cage to prevent such intrusion from occurring. A more detailed comparison of these experimental test devices will be included in a future paper.

Table 5. Experiment 1-3 Preliminary Injury Results for THOR

\begin{tabular}{|l|c|c|}
\hline \multicolumn{1}{|c|}{ Criteria } & $\begin{array}{c}\text { Injury } \\
\text { Threshold }\end{array}$ & $\begin{array}{c}\text { THOR male, } \\
\text { Window Seat }\end{array}$ \\
\hline HIC15 & 700 & 530 \\
\hline Nij & 1.0 & $\begin{array}{l}0.36(\mathrm{Ntf}) \\
0.41(\mathrm{Nte}) \\
0.16(\mathrm{Ncf}) \\
0.73(\mathrm{Nce})\end{array}$ \\
\hline Peak Neck Fz, lbf & $+937 /-899$ & $+585 /-209$ \\
\hline Chest G & 60 & 94 \\
\hline Femur Load, lbf & 2,250 & $904 / 1,328$ \\
\hline $\begin{array}{l}\text { Upper Abdomen } \\
\text { Compression Ratio } \\
\text { (mm) [16] }\end{array}$ & $50 \%$ & $30.2 \%$ \\
\hline $\begin{array}{l}\text { Upper Abdomen } \\
\text { V*C (m/s) [17] }\end{array}$ & 1.98 & 1.30 \\
\hline
\end{tabular}
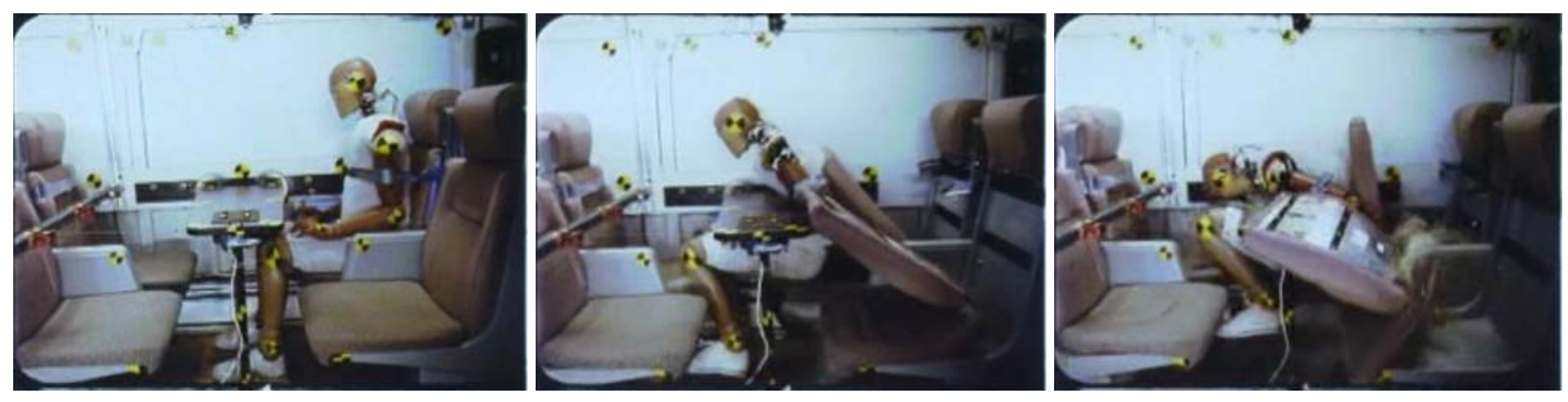

Figure 14. Time-Sequence for Experiment 1-3, THOR with Table, Leading Car 


\section{SUMMARY AND CONCLUSIONS}

Five interior occupant experiments were conducted as part of the two-car impact test of crash energy management equipment. Three of these experiments were similar to those conducted in previous full-scale impact tests such that injury results can be compared for impact tests involving conventional and CEM equipment. Two new experiments were conducted using tables and experimental dummies to analyze the risk of abdominal injury for occupants seated at tables.

The impact test described in this paper is the first in the series that utilized instrumented ATDs in CEM equipment. Based on computer modeling results, it was anticipated that the two-car CEM test would produce the most severe secondary impact environment of any test in the series. Preliminary test results confirm that the secondary impact environment in the two-car CEM test is indeed more severe than that of the previous tests. By quantifying the dynamic environment, interior modifications to mitigate the severity can be proposed, tested and evaluated. In fact, the rear-facing commuter seat experiment confirms the success of one potential remedy.

In spite of the severe collision environment, the measured injury results were generally lower than expected. Only a few injury thresholds were exceeded. No injury criteria were exceeded in the rear-facing seating configuration resulting in the lowest likelihood of injury among any of the configurations tested. While no injury criteria were exceeded in the forwardfacing commuter seat experiment, the load from the three ATDs was sufficient to cause severe deformation of the seat back, resulting in a loss of compartmentalization. The ATD in the forward-facing inter-city seats exceeded the head injury criteria.

The THOR and Hybrid 3RS experimental test dummies in the workstation table experiments provided information on the interaction of the abdomen with the table edge. These test dummies measured the abdominal compression and rate of compression, which will be used to estimate abdominal injury risk. The table was instrumented to measure the peak loads imparted by the occupant, which will be used to form standards for an improved table design. Further analysis of all the test data and computer model validation is on going.

In addition to rear-facing seating, other steps can be taken to reduce the effects of the more severe CEM crash pulse. Modifications to the interior can make the interiors less hostile during a collision. A reinforced commuter seat back will provide more resistance to deformation and increase the likelihood of compartmentalization. A more compliant intercity seat back will decelerate the occupant over a slightly larger distance, while still providing compartmentalization. An improved table design will limit and distribute the abdominal load while ensuring compartmentalization of the occupant.

The final test in the series of full-scale impact tests - a train-to-train test using crash energy management passenger equipment - is planned for 2005 . This test will incorporate all of the occupant experiment configurations described in this paper, as well additional experiments with ATDs in the locomotive and/or cab operator positions. The recommended seat and table modifications described above will be incorporated in the train-to-train test of CEM equipment, such that improved crashworthiness can be measured and evaluated.

\section{ACKNOWLEDGMENTS}

The research discussed in this paper was performed as part of the Equipment Safety Research Program sponsored by the Office of Research and Development of the Federal Railroad Administration. The authors would like to thank Dr. Tom Tsai, Program Manager, and Ms. Claire Orth, Division Chief, Equipment and Operating Practices Research Division, Office of Research and Development, Federal Railroad Administration, for their support, as well as Gunars Spons, FRA Resident Engineer at the Transportation Technology Center, for managing the full-scale test effort.

The authors would also like to thank Simula Technologies, Inc. for their work in implementing the occupant experiments, TTCI for implementing the structural aspects of the impact test, Mark Haffner, THOR Program Manager at the NHTSA National Transportation Biomechanics Research Center), for providing the THOR ATD, and the United Kingdom's Rail Safety and Standards Board, for providing the Hybrid 3RS ATD. Additional thanks go to A. Benjamin Perlman, Professor at Tufts University, for assistance in editing this paper.

\section{REFERENCES}

[1] VanIngen-Dunn, C., "Single Passenger Rail Car Impact Test Volume II: Summary of Occupant Protection Program," US Department of Transportation, DOT/FRA/ORD-00/02.2, March 2000.

[2] VanIngen-Dunn, C., "Passenger Rail Two-Car Impact Test Volume II: Summary of Occupant Protection Program," US Department of Transportation, DOT/FRA/ORD-01/22.II, January 2002.

[3] VanIngen-Dunn, C., "Passenger Rail Train-to-Train Test Volume II: Summary of Occupant Protection Program," US Department of Transportation, DOT/FRA/ORD-03/17.2, July 2003.

[4] Jacobsen, K., Tyrell, D., Perlman, A.B., "Impact Tests of Crash Energy Management Passenger Rail Cars: Analysis and Structural Measurements," American Society of Mechanical Engineers, Paper No. IMECE2004-61252, November 2004.

[5] Mayville, R., Johnson, K., Stringfellow, R. and D. Tyrell, "The Development of a Rail Passenger Coach Car Crush Zone," ASME/IEEE Joint Railroad Conference, paper number JRC20031653, Chicago, IL, April 2003.

[6] Severson, K., Tyrell, D., and A. B. Perlman, "Collision Safety Comparisons of Conventional and Crash Energy Management Passenger Rail Car Designs," paper number JRC2003-1657, ASME/IEEE Joint Railroad Conference, Chicago, IL, April 2003.

[7] Tyrell, D.C., Severson, K.J., Marquis, B.J., "Analysis of Occupant Protection Strategies in Train Collisions," ASME International Mechanical Engineering Congress and Exposition, AMD-Vol. 210, BED-Vol. 30, pp. 539-557, 1995.

[8] MADYMO 3D, Release 6.0/6.1, TNO Road-Vehicles Research Institute, Delft, The Netherlands.

[9] National Transportation Safety Board, "Collision of Burlington Northern Santa Fe Freight Train With Metrolink Passenger Train, Placentia, California, April 23, 2002" Railroad Accident Report NTSB/RAR-03-04, adopted on 10/7/2003. 
[10] Haffner, M., et al, "Foundations and Elements of the NHTSA THOR Alpha ATD Design," paper 458, presented at the $17^{\text {th }}$ International Technical Conference on the Enhanced Safety of Vehicles, Amsterdam, Holland.

[11] APTA SS-C\&S-034-99 Standard for the Design and Construction of Passenger Railroad Rolling Stock, The American Public Transportation Association, Washington, D.C.

[12] SAE J211-1 Surface Vehicle Recommended Practice Instrumentation for Impact Tests, March 1995.

[13] Severson, K., Tyrell, D., Perlman, A.B., "Rail Passenger Equipment Collision Tests: Analysis of Structural Measurements," Rail Transportation, American Society of Mechanical Engineers, RTD-Vol. 19, 2000.

[14] Eppinger, R., E. Sun, S. Kuppa, and R. Saul, "Development of Improved Injury Criteria for the Assessment of Advanced Automotive Restraint Systems - II," Supplement to NHTSA Docket No. 19984405-9, 2000.

[15] Code of Federal Regulations, Title 49, Part 571, Standard 208 Occupant Crash Protection, October 2002.

[16] Rouhana, S. W., Viano, D. C., Jedrzejczak, E. A., and McCleary, J. D., "Assessing Submarining and Abdominal Injury Risk in the Hybrid III Family of Dummies," Proc. 33 ${ }^{\text {rd }}$ Stapp Car Crash Conference, pp. 257-279, SAE Technical Paper No. 892440, October 1989.

[17] Wallace, W. Angus and Srinivasan, Sreebla C. M., "Rail Passenger \& Crew Survivability Studies - Part 2," November 2002.

\section{APPENDIX - RESULTS FROM PREVIOUS FULL- SCALE IMPACT TESTS}

Table A1. Injury Results from Conv. Single-Car Impact Test at 35 mph, Nov. 16, 1999

\begin{tabular}{|l|c|c|c|c|}
\hline \multirow{2}{*}{ Injury Criteria } & \multicolumn{2}{|c|}{$\begin{array}{c}\text { Commuter Seat, HIII } \\
50^{\text {th }} \text { Percentile Male }\end{array}$} & \multicolumn{2}{c|}{$\begin{array}{c}\text { Forward-Facing Inter-City } \\
\text { Seats }\end{array}$} \\
\cline { 2 - 5 } & $\begin{array}{c}\text { Forward- } \\
\text { facing }\end{array}$ & $\begin{array}{c}\text { Rear- } \\
\text { facing }\end{array}$ & $\begin{array}{c}\text { Restrained } \\
\text { HIII 5 } \\
\text { Female }\end{array}$ & $\begin{array}{c}\text { Unrestrained } \\
\text { HIII 95 } \\
\text { Male }\end{array}$ \\
\hline HIC36 & 202 & N/A & N/A & 854 \\
Neck Fx,lbf & $+242 /-45$ & N/A & $+15 /-70$ & $+1,510 /-99$ \\
Neck Fy, lbf & $+93 /-20$ & N/A & $+17 /-25$ & $+30 /-461$ \\
Neck Fz, lbf & $+327 /-45$ & $+226 /-62$ & $+251 /-68$ & $+539 /-710$ \\
Up Neck My, & $+37 /-17$ & $+29 /-47$ & $+22 /-14$ & $+305 /-44$ \\
ft-lbf & & & & N/A \\
Chest Gs & 14 & N/A & N/A & $-1,959$ \\
L. Femur, lbf & -671 & N/A & N/A & $-3,116$ \\
R. Femur, lbf & -806 & N/A & \multicolumn{3}{|c}{} \\
\hline
\end{tabular}

Table A2. Injury Results from Conv. Two-Car Impact Test at 26 mph, Commuter Seat Experiments, April 4, 2000

\begin{tabular}{|c|c|c|c|}
\hline \multirow{3}{*}{ Injury Criteria } & \multicolumn{3}{|c|}{ Commuter Seat, HIII $50^{\text {th }}$ Male } \\
\hline & \multicolumn{2}{|c|}{ Forward-facing } & Rear-facing \\
\hline & Leading Car & Trailing Car & Leading Car \\
\hline HIC36 & 69 & 118 & $\mathrm{~N} / \mathrm{A}$ \\
\hline Neck Fx, lbf & $+437 /-27$ & $+350 /-4$ & $+278 /-46$ \\
\hline Neck Fy, lbf & $+37 /-17$ & $+26 /-9$ & N/A \\
\hline Neck Fz, lbf & $+164 /-258$ & $+323 /-261$ & $+87 /-33$ \\
\hline Up Neck My, ft-lbf & $+148 /-8$ & $+91 /-42$ & $+10 /-16$ \\
\hline Chest Gs & 15 & 15 & $\mathrm{~N} / \mathrm{A}$ \\
\hline L. Femur, lbf & -556 & -646 & N/A \\
\hline R. Femur, lbf & -555 & -532 & $\mathrm{~N} / \mathrm{A}$ \\
\hline
\end{tabular}

Table A3. Injury Results from Conv. Two-Car Impact Test at 26 mph, Inter-City Seat Experiments, April 4, 2000

\begin{tabular}{|l|c|c|}
\hline \multirow{2}{*}{ Injury Criteria } & \multicolumn{2}{|c|}{$\begin{array}{c}\text { Forward-facing Inter-City Seats, Leading } \\
\text { Car }\end{array}$} \\
\cline { 2 - 3 } & $\begin{array}{c}\text { Restrained HIII } \\
5^{\text {th }} \text { Female }\end{array}$ & $\begin{array}{c}\text { Unrestrained HIII } \\
95^{\text {th }} \text { Male }\end{array}$ \\
\hline HIC36 & N/A & 593 \\
Neck Fx, lbf & $+20 /-70$ & $+897 /-60$ \\
Neck Fy, lbf & $+21 /-25$ & $+25 /-62$ \\
Neck Fz, lbf & $+168 /-68$ & No data \\
Upper Neck My, & $+22 /-14$ & $+209 /-13$ \\
ft-lbf & N/A & 28 \\
Chest Gs & N/A & -815 \\
L. Femur, lbf & N/A & $-2,765$ \\
R. Femur, lbf &
\end{tabular}

Table A4. Injury Results from Conv. Train-to-Train Impact Test at 30 mph, Commuter Seat Experiments, Jan. 31, 2002

\begin{tabular}{|l|c|c|}
\hline \multirow{2}{*}{ Injury Criteria } & \multicolumn{2}{|c|}{$50^{\text {th }}$ Male } \\
& \multicolumn{2}{|c|}{ Forward-Facing Commuter Seat, HIII } \\
\cline { 2 - 3 } & Leading Cab Car & $1^{\text {st }}$ Trailing Coach Car \\
\hline HIC15 & 16 & 10 \\
Neck Fx, lbf & $+199 /-100$ & $+139 /-59$ \\
Nij & $0.13(\mathrm{Ntf})$ & $0.8(\mathrm{Ntf})$ \\
Chest Gs & 6 & 5 \\
L. Femur, lbf & -183 & -185 \\
R. Femur, lbf & -43 & -179 \\
\hline
\end{tabular}

Table A5. Injury Results from Conv. Train-to-Train Impact Test at 30 mph, Inter-City Seat Experiments, Jan. 31, 2002

\begin{tabular}{|c|c|c|c|}
\hline \multirow[b]{2}{*}{ Injury Criteria } & \multicolumn{3}{|c|}{$\begin{array}{c}\text { Forward-facing Inter-City Seats, } \\
1^{\text {st }} \text { Trailing Coach Car }\end{array}$} \\
\hline & $\begin{array}{c}\text { Restrained } \\
\text { HIII } 5^{\text {th }} \\
\text { Female }\end{array}$ & $\begin{array}{l}\text { Unrestrained } \\
\text { HIII 95 } \\
\text { Male, Aisle } \\
\text { Seat, Aft } \\
\text { Row }\end{array}$ & $\begin{array}{c}\text { Restrained } \\
\text { HIII 95 } \\
\text { Male, } \\
\text { Window Seat, } \\
\text { Forward Row }\end{array}$ \\
\hline HIC15 & $\mathrm{N} / \mathrm{A}$ & 44 & $\mathrm{~N} / \mathrm{A}$ \\
\hline Neck Fx, lbf & $+67 /-64$ & $+75 /-418$ & $+107 /-60$ \\
\hline Nij & 0.32 (Nte) & 0.29 (Ncf) & 0.20 (Nte) \\
\hline Chest Gs & N/A & 5 & N/A \\
\hline L. Femur, lbf & N/A & -599 & N/A \\
\hline R. Femur, lbf & $\mathrm{N} / \mathrm{A}$ & -76 & N/A \\
\hline
\end{tabular}

